\title{
Síndrome de overlap: uma revisão de literatura da associação entre artrite reumatoide, espondilite anquilosante e síndrome de Sjögren
}

Overlap syndrome: a literature review of the coexistence of rheumatoid arthritis, ankylosing spondylitis and Sjögren's syndrome

Síndrome de superposición: una revisión de literatura de la asociación entre artritis reumatoide, espondilitis anquilosante y síndrome de Sjögren

Recebido: 21/08/2021 | Revisado: 28/08/2021 | Aceito: 30/08/2021 | Publicado: 01/09/2021

\author{
Bruno Balbino Macena \\ ORCID: https://orcid.org/0000-0001-5263-488X \\ Universidade Federal de Alfenas, Brasil \\ E-mail: brunobmacena@gmail.com \\ Letícia Martins Soares \\ ORCID: https://orcid.org/0000-0002-5588-104X \\ Universidade Federal de Alfenas, Brasil \\ E-mail: letmsoares1@gmail.com \\ Cristiane Mendes da Silva \\ ORCID: https://orcid.org/0000-0002-1382-6325 \\ Universidade Federal de Alfenas, Brasil \\ E-mail: cmsreumatologia@gmail.com
}

\begin{abstract}
Resumo
Síndrome de Overlap é o termo utilizado para descrever a associação de duas ou mais doenças - diagnosticadas independentemente - em um mesmo paciente. Neste artigo, os autores realizam uma revisão de literatura das principais publicações científicas acerca da associação entre Artrite Reumatoide, Espondilite Anquilosante e Síndrome de Sjögren em um mesmo paciente. O objetivo do estudo é construir um panorama das evidências disponíveis na literatura científica sobre casos de pacientes portadores desta associação tripla ou de outras associações duplas, como entre artrite reumatoide e espondilite anquilosante ou entre espondilite anquilosante e síndrome de Sjögren. Foram selecionados 16 artigos científicos entre 126 artigos escolhidos inicialmente nas principais bases de dados científicas nacionais e internacionais. Os resultados mostram que as características clínicas, radiológicas e sorológicos de cada doença podem estar presentes de forma parcial ou completa. Esta revisão nos alerta para a importância do estudo de associações pouco usuais devido à escassez de informações relevantes na literatura e, ao mesmo tempo, demonstra que a intervenção terapêutica precoce é essencial para uma melhora da qualidade de vida dos pacientes.
\end{abstract}

Palavras-chave: Síndrome de overlap; Artrite reumatoide; Espondilite anquilosante; Síndrome de Sjögren.

\begin{abstract}
Overlap Syndrome is a term used to describe the association of two or more independently diagnosed diseases in the same patient. In this article, the authors develop a literature review of the main studies published about the coexistence of ankylosing spondylitis with rheumatoid arthritis and Sjögren's syndrome. The aim of the study is to build an overview of the evidence available in the scientific literature on cases of patients with this triple association or other double associations, such as between rheumatoid arthritis and ankylosing spondylitis or between ankylosing spondylitis and Sjögren's syndrome. Sixteen scientific articles were selected among a hundred and twenty-six articles initially chosen in the main national and international scientific databases. The results show that the clinical, radiological and serological characteristics of each disease can be partially or completely present. The present review shows us the importance of studying unusual associations due to the lack of relevant information in the literature and at the same time indicates that early therapeutic intervention is essential to improve the quality of life of patients.
\end{abstract}

Keywords: Overlap syndrome; Rheumatoid arthritis; Ankylosing spondylitis; Sjögren syndrome.

\section{Resumen}

Una síndrome de superposición es un término utilizado para describir la asociación de dos o más enfermedades diagnosticadas de forma independiente en el mismo paciente. En este artículo, los autores desarrollan una revisión de la literatura de los principales estudios publicados sobre la coexistencia de espondilitis anquilosante con artritis reumatoide y síndrome de Sjögren. El objetivo del estudio es construir una visión general de la evidencia disponible en la literatura científica sobre casos de pacientes con esta triple asociación o otras dobles asociaciones, como entre 
artritis reumatoide y espondilitis anquilosante o entre espondilitis anquilosante y síndrome de Sjögren. Se seleccionaron dieciséis artículos científicos de entre ciento veintiséis artículos seleccionados inicialmente en las principales bases de datos científicas nacionales e internacionales. Los resultados muestran que las características clínicas, radiológicas y serológicas de cada enfermedad pueden estar presentes de forma parcial o total. La presente revisión nos muestra la importancia de estudiar asociaciones inusuales debido a la falta de información relevante en la literatura y, al mismo tiempo, demuestra que la intervención terapéutica precoz es fundamental para mejorar la calidad de vida de los pacientes.

Palabras clave: Síndrome de superposición; Artritis reumatoide; Espondilitis anquilosante; Síndrome de Sjögren.

\section{Introdução}

As doenças de cunho reumatológico constituem frequentemente um desafio para o médico generalista. A artrite reumatoide (AR) e a espondilite anquilosante (EA) são doenças autoimunes relativamente comuns, de características inflamatórias, crônicas e progressivas que levam ao dano articular e comprometimento funcional dos pacientes. A associação de ambas as patologias em um mesmo doente é rara e - por este motivo - há poucos relatos descritos na literatura. A maioria dos relatos foram descritos há mais de 40 anos, quando os critérios diagnósticos de cada doença ainda eram discutidos (Azevedo et al., 2013).

A artrite reumatoide possui uma prevalência estimada de 0,5-1\% e acomete principalmente mulheres entre 30 e 50 anos. Já a espondilite anquilosante ocorre em uma frequência de 0,1-0,5\% na população em geral. Alguns autores sugerem que a associação de ambas as doenças ocorre em uma frequência que varia entre 1/50.000 e 1/238.000 indivíduos, com a espondilite anquilosante geralmente se manifestando primeiro e em idade mais precoce. A síndrome de Sjögren possui uma predileção por mulheres de meia idade, com a proporção entre mulheres e homens de 9:1 e a prevalência estimada de sua forma primária é de 0,5-1\%. A incidência da coexistência entre a síndrome de Sjögren e a espondilite anquilosante é baixa. No entanto, Kobak (2006) observou uma alta prevalência de síndrome de Sjögren em pacientes com espondilite anquilosante $(10 \%)$ e, paralelamente a isso, a síndrome de Sjögren foi muito mais comum em mulheres com espondiloartropatias em alguns estudos (Guo et al., 2011; Mota et al., 2018; Ward et al., 2019; Kasper et al., 2020).

A manifestação de duas doenças autoimunes diagnosticadas independentemente em um mesmo doente caracteriza a síndrome de overlap. Uma grande gama de associações é descrita na literatura, porém, as duas mais referidas incluem o lúpus eritematoso sistêmico (LES) e a artrite reumatoide, e a coexistência de esclerodermia sistêmica (ES) e dermatomiosite (DM). Existe uma alta prevalência de coexistência entre doenças autoimunes em pacientes portadores de síndrome de Sjögren. Rojasvillarraga et al. (2012) conduziu uma revisão sistemática na qual observou uma prevalência de 55,6\% de casos de síndrome de Sjögren em uma coorte de 142 pacientes portadores de múltiplas doenças autoimunes. O diagnóstico da síndrome de overlap implica a valorização de alterações clínicas e fisiológicas típicas das entidades nosológicas envolvidas. A presença de autoanticorpos também deve ser pesquisada, especificamente, o fator antinuclear (FAN), fator reumatoide (FR), autoanticorpos contra Peptídeo Citrulinado Cíclico (Anti-CCP) e o Antígeno Leucocitário Humano B27 (HLA B27) (Azevedo et al., 2013).

Conforme supracitado, a associação da artrite reumatoide e espondilite anquilosante em um mesmo paciente é pouco usual. Azevedo et al. (2013) publicou um relato dessa concomitância na Revista Brasileira de Reumatologia. Eles também realizaram uma revisão de literatura na qual compararam as principais características de casos previamente reportados com o caso descrito. Desde então, nenhum outro caso dessa natureza foi publicado na literatura brasileira. O objetivo do presente estudo é construir um panorama das evidências disponíveis na literatura científica sobre casos de pacientes portadores de uma associação tripla entre artrite reumatoide, espondilite anquilosante e síndrome de Sjögren; e também discutir os casos de pacientes que possuem uma associação dupla entre artrite reumatoide e espondilite anquilosante ou entre espondilite anquilosante e síndrome de Sjögren. 


\section{Referencial teórico}

\subsection{Artrite Reumatoide}

A artrite reumatoide (AR) é uma doença complexa, com associação de fatores genéticos e ambientais ainda não completamente elucidados. É uma doença tipicamente de imunidade celular - com predomínio de citocinas inflamatórias (IL1, IL-6 e TNF- $\alpha$ ). Há ligação observada com o HLA tipo 2 DR4 (não-próprio), acreditando-se ser resposta a um agente infeccioso ainda não identificado. Todo esse conjunto de citocinas e células imunológicas leva a uma infiltração articular, especialmente na membrana sinovial, com destruição e desenvolvimento de fibrose local - artrite erosiva (Laurindo et al., 2007)

O quadro clínico marcante é uma poliartrite simétrica erosiva aditiva com rigidez matinal. Apesar dos exames complementares serem importantes, o diagnóstico é predominantemente clínico. A manifestação clínica geralmente é insidiosa, podendo haver pródromos como - fadiga, astenia, enrijecimento articular e mialgia. Com a evolução, inicia-se a artrite poliarticular simétrica geralmente de mãos, punhos, pés, joelhos e cotovelos. A coluna cervical também pode ser acometida, no entanto, outras partes são extremamente incomuns. A artrite faz com que as articulações acometidas se tornem quentes, dolorosas e edemaciadas. Somado a isso, a rigidez matinal (geralmente maior que 1 hora) leva o paciente a ter dificuldade em abrir torneiras, portas e realizar outras atividades do cotidiano por exemplo. A artrite crônica leva à atrofia muscular periarticular e, com o avanço da doença, deformidades articulares importantes podem ser observadas ("dedos em pescoço de cisne", "dedos em casa de botão", "dedos em martelo"). A artrite de punho pode gerar concomitante Síndrome do Túnel do Carpo (Mota et al., 2011).

$\mathrm{Na}$ suspeita clínica, os exames complementares que devem ser solicitados pelo atendimento primário são: hemograma completo, velocidade de hemossedimentação (VHS), proteína C reativa quantificada (PCR), fator reumatoide (FR) e radiografias de punho e tórax. Considerando apenas a AR, o hemograma completo pode estar normal ou com anemia normocítica e normocrômica. Em alguns casos, é possível observar anemia hipocrômica. Em relação às provas de atividade inflamatória, 66\% dos pacientes apresentarão valores aumentados de VHS e/ou PCR. O FR tem sensibilidade média de 60\%, sendo assim, 40\% dos pacientes terão AR mesmo com FR negativo. Isso reforça a AR como diagnóstico clínico. Por outro lado, pacientes podem ter FR positivo mesmo sem possuir AR - alguns idosos tem FR positivo mesmo sem patologias e o FR também está presente em outras doenças como lúpus eritematoso sistêmico, pneumoconioses, leucemia, hepatites, tuberculose etc. Dois outros exames laboratoriais devem ser mencionados: o FAN e o anti-CCP. Quinze por cento dos pacientes com AR podem apresentar FAN positivo. Quanto ao Anti-CCP, ele possui sensibilidade de 80\% e especificidade de 95\% - ou seja, a taxa de falsos-positivos é de 5\%. É, portanto, um marcador mais específico da AR (Shafia et al., 2013).

O tratamento não-farmacológico consiste basicamente na conscientização do paciente sobre a doença, sua cronicidade e, eventualmente, sua condição incapacitante, especialmente nos momentos de exacerbação. Outra parte do tratamento nãomedicamentoso é a fisioterapia. É sabido que o calor local reduz a rigidez articular, com alívio dos sintomas. A realização de exercícios também melhora a saúde articular, melhorando o prognóstico do paciente. Já o tratamento farmacológico é composto por dois grupos: sintomáticos e drogas modificadoras do curso da doença (DMARD - Disease Modifying Antirheumatic Drugs). Entre os sintomáticos, podem-se usar anti-inflamatórios não-esteroidais ou corticoides. Os DMARDs são drogas de ação lenta que mudam o curso evolutivo da doença diminuindo o processo erosivo e incapacitante. O início da ação desses fármacos ocorre entre 60 e 120 dias, necessitando o médico persistir o uso mesmo sem melhora clínica nessa fase inicial. Nesse tempo, o uso de sintomáticos pode ser associado. O DMARD de primeira escolha para o paciente que ainda não fez uso dessa classe de medicamentos e que possui doença classificada como moderada ou severa é a monoterapia com o metotrexato. Por outro lado, para o paciente que possui uma baixa atividade da doença e não recebeu tratamento prévio com DMARD, a hidroxicloroquina é uma escolha superior aos DMARDs sintéticos convencionais em decorrência de uma melhor 
tolerância por parte do paciente e um perfil de risco menos danoso. O metotrexato oral deve ser preferido em decorrência de sua maior facilidade de administração e biodisponibilidade semelhante ao metotrexato subcutâneo. Apesar dessa recomendação, alguns estudos sugerem que o medicamento por via oral é menos eficaz. Para os pacientes que não toleram ou não atingem o alvo terapêutico, dividir a dose dentro das 24 horas (em caso de intolerância) e alternar para injeções subcutâneas são alternativas para solucionar esses problemas (Shah, 2013; Fraenkel et al., 2021).

Sugere-se encaminhamento para serviço especializado em reumatologia pacientes com:

- Diagnóstico de AR estabelecido com pontuação maior ou igual a 6 pelos critérios classificatórios de 2010 do ACR (Aletaha, D. et al., 2010; ACR/EULAR, 2010);

- Alta suspeita de AR definida pela presença de artrite (sinovite ou edema identificado pelo médico) de 3 ou mais articulações associadas à rigidez matinal por mais de 30 minutos e/ou teste do squeeze positivo (Aletaha, D. et al., 2010; ACR/EULAR, 2010).

\subsection{Espondilite Anquilosante}

A espondilite anquilosante (EA) é uma doença de característica inflamatória, crônica, progressiva, assimétrica, autoimune, que acomete as articulações sacroilíacas, a coluna vertebral em graus variáveis e, em menor extensão, as articulações periféricas, causando a eventual fusão das articulações axiais envolvidas (Chiarello et al., 2015).

Afeta principalmente o sexo masculino, cujo início ocorre, em média, entre os 20 e 40 anos de idade. Da mesma forma que a artrite reumatoide, é uma doença progressiva e evolui com surtos inflamatórios e processos de agudização, os quais seguem-se por períodos mais ou menos longos de remissão (Gabriel et al., 2011).

Geralmente, inicia-se pelas articulações sacroilíacas, progride para a coluna, acometendo articulações discais, zigoapofisárias, ligamento intervertebral comum anterior, ligamento intervertebral comum posterior, ligamentos amarelos, ligamentos interespinhosos, ligamentos supraespinhosos e ligamentos transversos, podendo, ainda, estender-se de modo centrífugo para as articulações mais periféricas (Mendes et al., 2005).

Os sintomas da doença começam no final da adolescência ou no início da idade adulta e podem ser caracterizados, em um momento inicial, por febre, fadiga e anorexia. A queixa principal é de dor insidiosa na região lombar baixa e na parte inferior da região glútea, rigidez matinal ou após o repouso, que melhora com exercício ou movimento. Ocorre retificação da lordose lombar com atrofia dos músculos da região glútea, acentuação da cifose torácica e envolvimento cervical. Se houver contratura do músculo iliopsoas, o paciente faz uma genoflexão para compensar. Essa postura é conhecida como "postura do esquiador" ou postura espondilítica. A redução da mobilidade da coluna pode provocar dor aguda, espasmos musculares, contratura de tecido mole ou anquilose de áreas específicas. Diversas articulações periféricas podem ser afetadas por entesopatias, contratura dos tecidos moles ou anquilose. As articulações sacroilíacas são as mais comumente afetadas, apresentando condrite e osteíte subcondral, sendo observada radiologicamente como um pseudo-alargamento da interlinha articular, evoluindo progressivamente com anquilose da articulação sacroilíaca (Chiarello et al., 2015).

O diagnóstico das Espondiloartrites Axiais é realizado utilizando os critérios de 2010 da ASAS (Assessment of SpondyloArthritis International Society) (ASAS, 2010). Para o diagnóstico, é necessário 1 critério clínico e 1 radiológico; A é critério obrigatório; B e C são critérios possíveis:

a) Lombalgia inflamatória por 3 meses em paciente com menos de 45 anos;

b) Sacroilíite em exames de imagem ${ }^{1}$ e, pelo menos, 1 característica de espondiloartrite;

c) HLA-B27 e 2 ou mais características de espondiloartrite ${ }^{2}$

${ }^{1}$ Radiografia simples (com sacroiliíte bilateral graus 2-4 ou unilateral graus 3 e 4) ou ressonância magnética de articulações sacroilíacas (com edema ósseo medular subcondral/ osteíte). 
${ }^{2}$ Características de espondiloartrite: lombalgia inflamatória, artrite periférica, entesite, uveíte, psoríase, doença de Crhon ou retocolite ulcerativa, história familiar de espondiloartropatia, boa resposta ao uso de AINEs, HLA-B27, proteína C reativa elevada.

O diagnóstico da espondilite anquilosante é realizado utilizando os critérios modificados de Nova Iorque de 1985 (Van Der Linden, S. et al., 1984; ASAS, 2010). É útil para doença estabelecida. Para o diagnóstico, é necessário 1 critério clínico e 1 radiológico. São considerados:

Critérios clínicos:

a) Lombalgia inflamatória por mais de 3 meses que melhora com o exercício físico;

b) Limitação dos movimentos da coluna lombar nos planos frontal (Teste de Schober $<5$ ) e sagital (variação média bilateral dedo-chão inferior a $10 \mathrm{~cm}$ );

c) Expansão torácica diminuída (inferior a 2,5cm).

Critérios radiológicos:

a) Radiografia com sacroiliíte bilateral graus 2-4;

b) Radiografia com sacroiliíte unilateral graus 3 ou 4 .

A maioria dos pacientes é tratada através do controle dos sintomas, associado a um programa de exercícios físicos que mantêm e melhoram a mobilidade da coluna e a postura, minimizam as deformidades e diminuem as limitações físicas. Os pacientes podem obter um alto nível de independência se o tratamento correto for instituído (Gabriel et al., 2011).

A severidade de envolvimento articular e o grau de sintomas sistêmicos podem variar muito de um indivíduo para outro. Um diagnóstico precoce e preciso, levando ao tratamento correto, pode minimizar anos de dor e inaptidão. A primeira linha para o tratamento da espondilite anquilosante ativa no adulto se baseia no uso de anti-inflamatórios não esteróides (AINEs). Para os pacientes com doença ativa apesar do uso de AINEs e que apresentam artrite periférica importante, ou na indisponibilidade dos inibidores do fator de necrose tumoral, a sulfassalazina e o metotrexato devem ser considerados, sendo o primeiro medicamento superior ao segundo. $\mathrm{O}$ tratamento com inibidores do fator de necrose tumoral é altamente recomendado no paciente que, a despeito do uso de AINEs, ainda apresenta a doença em atividade. Exercícios de solo também são essenciais, principalmente se iniciados precocemente (Rezende, 2016; Ward et al., 2019).

Os princípios básicos para o tratamento são: aliviar a dor e as contraturas, prevenir deformidades, evitar atrofias musculares, proteger as articulações afetadas, estagnar a deformidade articular e atrofia muscular quando já instaladas, desenvolver a função mioarticular e reabilitar profissionalmente o paciente (Mendes et al., 2005).

O tratamento cirúrgico é realizado em casos extremamente específicos, como fratura de coluna por trauma ou pseudoartrose, deformidade espinhal progressiva, instabilidade de rotação secundária à luxação atlanto-occipital ou atlantoaxial e estenose espinhal (Chiarello et al., 2015).

\subsection{Síndrome de Sjögren}

A síndrome de Sjögren (SSi) é uma doença autoimune, de caráter crônico, caracterizada por xerostomia, xeroftalmia e está, em alguns casos, associada a doenças do colágeno, como a artrite reumatoide. Apresenta relevância no campo da odontologia em virtude das complexas alterações que podem ser observadas nas glândulas salivares e, consequentemente, em toda a cavidade oral. As manifestações nessa região são por vezes as primeiras a serem notadas. O tratamento envolve acompanhamento multiprofissional através da atuação do cirurgião dentista, oftalmologista e reumatologista, objetivando a busca por melhor qualidade de vida e saúde para o paciente (Lawall et al., 2006).

Embora as glândulas lacrimais e salivares sejam os principais órgãos afetados pela infiltração linfo-plasmocitária, 
outras glândulas exócrinas também podem ser acometidas, como pâncreas, glândulas sudoríparas, glândulas mucosas dos tratos respiratório, gastrointestinal e urogenital. Pode ser primária ou secundária a determinadas doenças do colágeno. Contudo, sabese que fatores ambientais como infecções virais prévias (vírus Epstein-Barr, citomegalovírus, herpes vírus humano, vírus da hepatite C, dentre outros) ou mesmo bacterianas (Helicobacter pylori) podem ser prováveis gatilhos para a resposta inflamatória autoimune contra o tecido glandular em decorrência da frequência de concomitância entre essas patologias. A relação entre mulheres e homens acometidos é de 9:1, o que pode acusar uma influência hormonal na fisiopatologia da doença (Felberg et al., 2006).

O paciente pode manifestar sintomas a nível ocular como secura, irritação, sensação de corpo estranho, queimação, fotofobia e turvação; sendo essas mais frequentes do que as orais nas formas secundárias de SSi. As manifestações orais incluem, além das já mencionadas, cáries frequentes, dificuldade na deglutição de alimentos sólidos, dor à deglutição, aftas e úlceras, necessidade de umedecer a boca frequentemente e de ingerir líquidos, maior incidência de infecções bucais, entre outros. Pode haver manifestações musculoesqueléticas como dores, além de fadiga, miosite, mialgia, artralgia e artrite; cutâneas como despigmentações, eritemas, prurido e eczemas; vasculares como fenômeno de Raynaud, trombose venosa profunda e vasculite; manifestações neurológicas e, por fim, transtornos psiquiátricos como ansiedade, depressão e distúrbios de personalidade (Felberg et al., 2006).

Anti-SSA/Ro e anti-SSB/La são anticorpos contra ribonucleoproteínas encontrados com muita frequência nesses pacientes, principalmente na forma primária da doença. Já o fator reumatoide e o fator antinuclear são mais frequentes na SSi secundária (Felberg et al., 2006).

Os critérios usados para a classificação da síndrome de Sjögren primária, de acordo com as diretrizes da ACR/EULAR 2016 (Shiboski et al., 2017), para pacientes com pelo menos um sintoma compatível com xerostomia ou xeroftalmia ou para indivíduos em que exista a suspeita de síndrome de Sjögren com base em um dos domínios da EULAR Sjögren's Syndrome Disease Activity Index (ESSDAI) são:

a) Glândula salivar labial com sialadenite linfocítica focal e pontuação de foco $>$ ou $=1$ foci/ $4 \mathrm{~mm}^{2}$;

b) Anti-SSA/Ro positivo;

c) Pontuação de coloração ocular > ou $=5$ (ou pontuação de van Bijsterveld > ou $=4$ em pelo menos um olho);

d) Teste de Schirmer $<$ ou $=5 \mathrm{~mm} / 5 \mathrm{~min}$ em pelo menos um olho;

e) Taxa de fluxo de saliva total não estimulada $<$ ou $=0,1 \mathrm{~mL} / \mathrm{min}$.

Os novos critérios se baseiam em uma soma dos pesos atribuídos a cada um dos itens. A biópsia glandular e a pesquisa pelo anticorpo receberam peso três. Já a pontuação de coloração ocular, o teste de Schirmer e a taxa de fluxo salivar contribuem cada um com peso um. É importante observar que, diferente das classificações prévias, a presença de anti-SSB/La na ausência de anti-SSA/Ro não é mais considerada como um critério para diagnóstico. O individuo que apresenta uma pontuação de quatro ou mais pode ser considerado portador da síndrome de Sjögren primária (Shiboski et al., 2017).

Para o diagnóstico de SS secundária, tem-se:

a) Presença de artrite reumatoide ou outra doença do tecido conjuntivo;

b) Presença de sintomas oculares ou orais associados a pelo menos 2 dos seguintes itens: evidência objetiva de envolvimento ocular, critério histopatológico e evidência objetiva de envolvimento da glândula salivar. Os anticorpos não entram como critério nesse caso (Vitali et al., 2002).

Em relação ao tratamento sintomático da secura, a região oral se beneficia de substitutos da saliva e devem idealmente conter flúor, bactericidas e soluções tamponadas que ajudem no combate do biofilme. Estimuladores mecânicos e/ou químicos gustatórios, como balas e gomas de mascar sem açúcar podem ser úteis. Soluções contendo ácido mélico, flúor e xilitol têm eficácia semelhante ao estimulante tradicional com ácido cítrico, mas apresentam a vantagem de manter um pH mais elevado. 
Em casos leves de secura ocular, o paciente pode fazer uso de colírios e deve obedecer a medidas preventivas. Em casos moderados, pode fazer uso de Ciclosporina tópica ou Ômega 3; em casos graves, pode fazer uso de agentes muscarínicos e realizar oclusão de ponto lacrimal. Esse sintoma em outros sítios demanda educação do paciente e medidas preventivas, além de N-acetilcisteína (Valim et al., 2015).

O tratamento de primeira linha para a artrite é educação, fisioterapia, corticosteroide ou hidroxicloroquina. Para a miosite, glicocorticoide, enquanto a mialgia, fadiga e artralgia se beneficiam de educação do paciente e exercícios aeróbicos. Em relação às manifestações neurológicas, condições como a polineuropatia sensitiva, vasculite de sistema nervoso central e mononeurite múltipla podem ser abordadas através de pulsoterapia com metilprednisolona e ciclofosfamida. A meningite, através do uso de glicocorticoides. As vasculites também se beneficiam com o uso de pulso de metilprednisolona. Estes se classificam como tratamento de primeira linha para estas condições (Valim et al., 2015).

\section{Metodologia}

Trata-se de uma revisão de literatura, que explorou bases científicas nacionais e internacionais, com o tema central: "a coexistência de artrite reumatoide, espondilite anquilosante e síndrome de Sjögren em um mesmo paciente". A variada estrutura de amostragem das revisões de literatura, em conjunto com a multiplicidade de propósitos, tem o potencial de reunir as principais informações e discussões extraídas das publicações em estudo.

Para conduzir esta revisão de pesquisa, delineou-se os seguintes processos: identificação da linha principal de pesquisa; busca na literatura dos estudos condizentes com a temática; avaliação do tema central; descrição detalhada do caso clínico; protocolos e diretrizes utilizados na abordagem diagnóstica e terapêutica e, por fim, avaliação, análise e síntese dos dados estatísticos. Como ponto de partida, foi estabelecida uma pergunta norteadora a ser respondida: "como se caracterizam as principais manifestações clínicas e laboratoriais nos pacientes portadores da associação entre artrite reumatoide, espondilite anquilosante e síndrome de Sjögren?".

Norteados por essa indagação, foi seguido um rigoroso processo de captura, seleção e sistematização dos artigos cujos passos estão descritos, sequencialmente, a seguir: inicialmente, os artigos foram extraídos das bases de dados Elsevier, Scielo, Lilacs e PubMed, eleitos por sua abrangência e reconhecida relevância para a divulgação do conhecimento produzido na área da saúde. Além destas, outras bases de dados, algumas de acesso limitado, também foram consultadas, como a Web of Science, Scopus e Revista Brasileira de Reumatologia. Não foram ignorados, contudo, importantes dados existentes em bancos de teses de mestrado, de doutorado, de outros trabalhos de conclusão de curso, revisões de livros e anais de eventos científicos nacionais e internacionais, que, embora passem por um crivo avaliativo diferente dos artigos científicos, também merecem uma atenção específica.

Como delimitador, foi estabelecido um período máximo de quarenta anos, mais especificamente, de janeiro de 1981 a fevereiro de 2021, verificando, assim, todos os textos disponíveis na íntegra, sem nenhuma restrição de idioma.

Diante dos 16 artigos selecionados, identificaram-se determinadas informações como título, ano de publicação, país de origem, área de concentração, objetivo, estratégia de coleta de dados utilizada e patologias associadas - aqui, cabe uma importante observação para o fato de que, devido à relevante escassez na literatura de publicações acerca da associação das três doenças em estudo, outras publicações de associações duplas, como a associação entre artrite reumatoide e espondilite anquilosante ou entre artrite reumatoide e síndrome de Sjögren, também foram incluídas no estudo.

O processo de captura das publicações e análise de dados foi realizado concomitantemente pelos dois autores deste estudo, que desenvolveram esse trabalho de forma conjunta. Esses dados foram sistematizados individualmente em planilhas e grupos de texto nos softwares Microsoft Excel e Microsoft Word, dos quais foram extraídos os dados que foram organizados e apresentados em categorias de resultados e discussão, respondendo aos objetivos deste estudo. 
Para a elaboração do formato de revisão de literatura, também foram utilizados artigos científicos que tratam desta temática, sobretudo, o artigo The Integrative Review: uptaded methodology, de Robin Whittemore e Kathleen Knalf.

\section{Resultados}

Foram encontrados 126 artigos. Após a remoção dos duplicados e através de uma análise criteriosa dos títulos e resumos dos relatos por ambos os revisores, foram encontrados 16 textos que contemplavam o tema abordado, com apenas 2 desses retratando a coexistência das três doenças em um mesmo paciente (TABELA 1). Quatro dos relatos abordam pacientes que desenvolveram tanto espondilite anquilosante quanto síndrome de Sjögren, e os outros 10 abordam a associação entre espondilite anquilosante e artrite reumatoide (TABELA 2).

Clayman e Reinertsen (1978) relatam o caso de um homem branco de 48 anos de idade, que apresentou de forma concomitante e clara EA e AR severa com nódulos subcutâneos, SSi e vasculite. Aos 21 anos, o paciente relatou dor e rigidez predominantemente matinais na região lombar e tornozelos. O diagnóstico de EA foi realizado. Porém, mesmo com a implementação de anti-inflamatórios e terapias de irradiação, não houve melhora, o que resultou na anquilose das articulações acometidas. Aos 33 anos, o paciente referiu rigidez matinal importante e edema simétrico das articulações do pulso, metacarpofalangeanas, interfalangeanas proximais e metatarsofalangeanas, associado a uma importante fadiga e positividade do fator reumatoide detectado através de exames. Foi firmado o diagnóstico de artrite reumatoide. $\mathrm{O}$ tratamento com aurotioglucose (sais de ouro), apesar de ser o único a proporcionar alívio, foi interrompido devido à estomatite recorrente (Clayman et al., 1978).

No ano anterior à admissão, o paciente nota desenvolvimento de xeroftalmia e xerostomia e, nos quatro meses anteriores, cursa com lesões puntiformes eritematosas nos membros inferiores, cuja biópsia revelou se tratar de vasculite crônica. Também foi relatado caso de artrite em avô paterno, de acordo com histórico familiar. Ao exame: redução na amplitude do movimento das articulações do ombro e cotovelo, desvio ulnar e subluxações das articulações metacarpofalangeanas, bem como o comprometimento da articulação talocrural, do quadril, do pulso, joelhos, interfalangeanas proximais e metatarsofalangeanas. Os exames laboratoriais evidenciaram redução do hematócrito e volume corpuscular médio da hemácia, VHS de 114 (acima do valor de referênciade até $15 \mathrm{~mm} / \mathrm{h}$ ). Esse é um importante exame para identificar processos inflamatórios, BFT (bentonite flocculation test) positivo, níveis de imunoglobulinas elevados (IgG $21.0 \mathrm{mg} / \mathrm{ml}$, IgM 3.0 $\mathrm{mg} / \mathrm{ml}$, IgA $6.1 \mathrm{mg} / \mathrm{ml}$ ) e presença de HLA-B27. Os exames de imagem comprovam os achados característicos das doenças: fusão das articulações da coluna e obliteração da articulação sacroilíaca; erosões, subluxações e perda do espaço articular nas articulações das mãos e alterações menos expressivas em outras. As taxas de fluxo salivar estimulado por suco de limão foram de 0.75 ml/glândula/ 5 minutos (valor normal: > ou = 1) (Clayman et al., 1978).

Tabela 1 - Casos de associação entre EA, AR e SSi relatados na literatura.

\begin{tabular}{|l|l|l|l|l|l|l|} 
Referência & \multicolumn{1}{l}{$\begin{array}{l}\text { Idade de início } \\
\text { (EA/AR/SS) }\end{array}$} & Sexo & FR* & HLA-B27 & DLI*** & $\begin{array}{l}\text { Anquilose } \\
\text { sacroilíaca }\end{array}$ \\
\hline $\begin{array}{l}\text { Clayman e } \\
\text { Reinertsen, } \\
\mathbf{1 9 7 8}\end{array}$ & M & + & + & + & + \\
\hline $\begin{array}{l}\text { Zhao et al., } \\
\mathbf{2 0 2 0}\end{array}$ & $30 / 42 / 45$ & $\mathrm{M}$ & + & + & + & + \\
\hline
\end{tabular}

*FR: fator reumatoide. **DLI: dor lombar inflamatória. Fonte: Autores. 
Tabela 2 - Casos de associação entre EA e AR relatados na literatura.

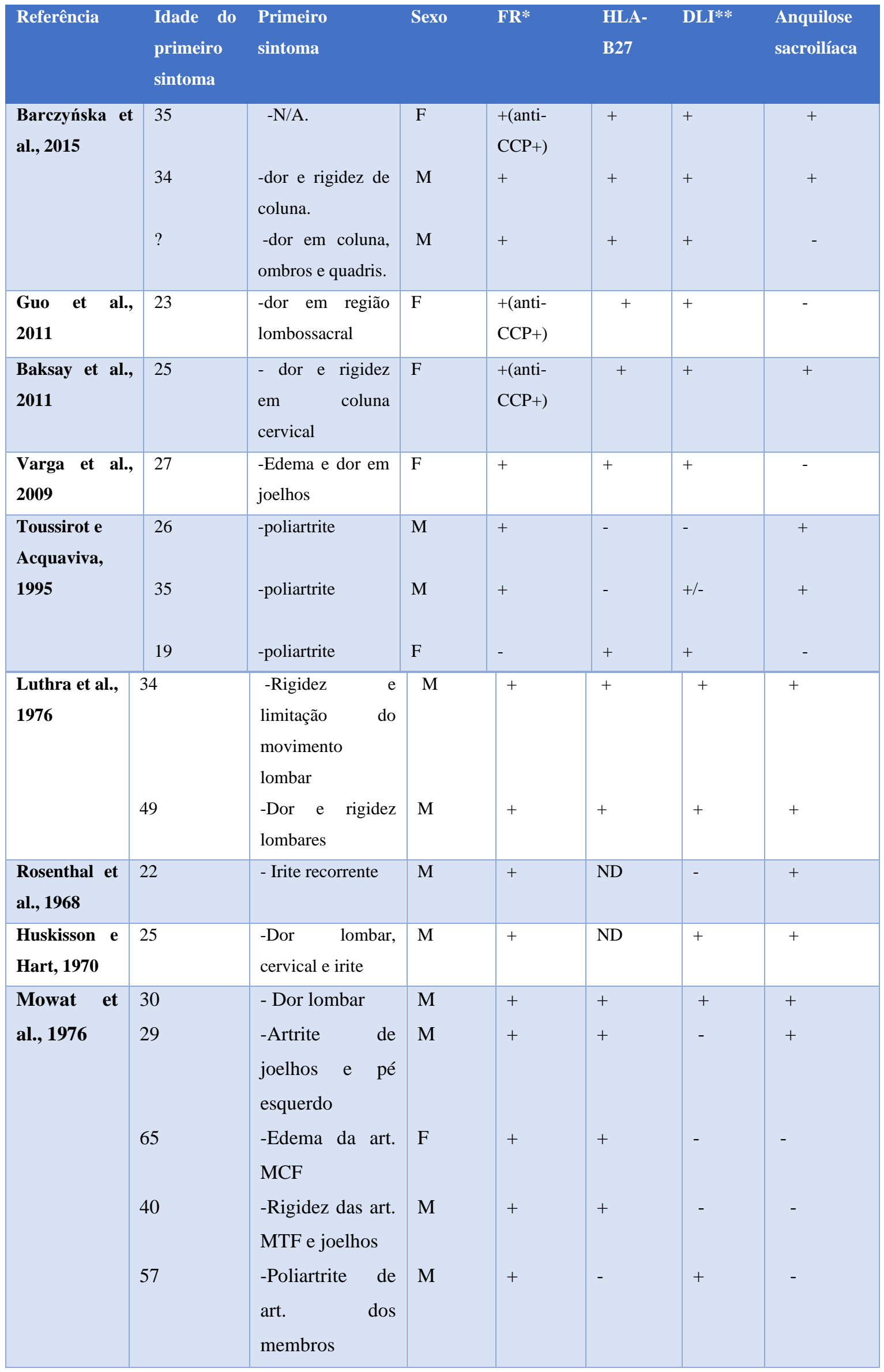




\begin{tabular}{|c|c|c|c|c|c|c|c|}
\hline & $\begin{array}{l}42 \\
29\end{array}$ & $\begin{array}{l}\text {-Dor lombar e } \\
\text { cervical } \\
\text {-Irite } \\
\text {-Dor em região } \\
\text { sacroilíaca } \\
\text {-Dor e rigidez } \\
\text { lombares }\end{array}$ & $\begin{array}{l}\mathrm{F} \\
\mathrm{M} \\
\mathrm{M}\end{array}$ & $\begin{array}{l}+ \\
+\end{array}$ & $\begin{array}{l}+ \\
+\end{array}$ & $\begin{array}{l}- \\
+\end{array}$ & $\begin{array}{l}- \\
+\end{array}$ \\
\hline $\begin{array}{l}\text { Wilkinson } \\
\text { e Bywaters } \\
1958\end{array}$ & 40 & -Dor lombar & $\mathrm{M}$ & - & ND & + & N/D \\
\hline
\end{tabular}

*FR: fator reumatoide. **DLI: dor lombar inflamatória. MCF: metacarpofalangeanas. MTF: metatarsofalangeanas. Fonte: Autores.

Barczyńska et al. (2015) relata o caso de 3 pacientes, uma mulher e dois homens. Uma mulher de 55 anos, com diagnóstico pregresso de artrite reumatoide (20 anos antes), exibiu dor e edema simétricos das articulações das mãos, pés, pulso e quadril esquerdos, além de dor em coluna de caráter inflamatório e que apresentou piora significativa nos 18 meses anteriores ao relato. Sinais de doença avançada como distorção das articulações das mãos e redução da mobilidade da coluna (principalmente cervical) foram encontrados (Barczyńska et al., 2015).

O segundo paciente, um homem de 56 anos, teve como primeira manifestação sintomas de espondilite anquilosante aos 34 anos. 14 anos depois, cursou com poliartrite simétrica das articulações periféricas (mãos, pés, pulsos) (Barczyńska et al., 2015).

O terceiro paciente cursou com as mesmas manifestações clínicas descritas. Contudo, as idades de início dos sintomas não foram expostas no artigo, mas sabe-se que a dor na coluna de caráter inflamatório precede as manifestações da artrite reumatoide. Todos os 3 casos cursaram com subluxações e/ou erosões na radiografia das mãos e dos pés (Barczyńska et al., 2015).

Guo et al. (2011) descreve o caso de uma mulher de 30 anos que possui um histórico de dor em região lombossacral iniciada aos 23 anos. Para controle da doença, foram prescritos meloxicam, sulfasalazina e hidroxicloroquina. Contudo, apesar da melhora, a paciente interrompeu o uso das medicações por 2 anos em decorrência da gravidez e, um ano antes de procurar ajuda médica, desenvolveu dor e rigidez matinais simétricas nas mãos e cotovelos. Exames de imagem demonstraram fusão dos ossos do carpo. Foram prescritos DMARDs, leflunomida e hidroxicloroquina (Guo et al., 2011).

Baksay et al. (2011) descreve o caso de uma mulher que, aos 25 anos, alguns meses após conceber seu filho, desenvolveu dor e rigidez de coluna cervical, tendo o diagnóstico de espondilite anquilosante confirmado alguns anos depois. Aos 51, o padrão de envolvimento se alterou, e a paciente passou a apresentar dor e rigidez matinal superior a 3 horas nas pequenas articulações das mãos e pés. A radiografia demonstrou erosões marginais em mãos e pés e coluna em bambu. Metilprednisolona e metotrexato foram prescritos (Baksay et al., 2011).

Varga et al. (2009) descreve um caso atípico de uma mulher de 35 anos, com história pregressa de gastroenterite por Salmonella e infecção de via aérea superior por Mycoplasma pneumoniae, que desenvolveu em ambas as ocasiões edema e dor em ambos os joelhos, sendo diagnosticada uma provável artrite reativa. A condição posteriormente evoluiu para comprometimento simétrico também dos punhos e articulações metacarpofalangeanas. Foi feito uso de metilprednisolona e introduzida a sulfasalazina. Após gestação em 2005, a paciente retorna em 2007 com queixas de dor e rigidez em coluna e quadril, com remissão do quadro articular anterior, e a radiografia demonstrou presença de erosões e sacroiliíte. Em face do 
diagnóstico de espondilite anquilosante, a terapia com bloqueador de TNF-alfa foi implementada (Varga et al., 2009).

Toussirot e Acquaviva (1995) conduziram um estudo retrospectivo com o objetivo de determinar a frequência da positividade do HLA-B27 em pacientes portadores de artrite reumatoide hospitalizados durante os últimos 5 anos em um hospital da França $(n=130)$. O mesmo foi feito para determinar a ocorrência do fator reumatoide em pacientes com espondilite anquilosante $(\mathrm{n}=87)$. Não houve relevância estatística nesses valores ao serem comparados com a prevalência desses marcadores sorológicos na população geral e grupo controle respectivamente. Esse estudo também teve o objetivo de identificar casos de associação genuína entre essas duas doenças, encontrando um total de 3 casos. O primeiro descreve um homem de 48 anos que desenvolveu artrite reumatoide aos 26 e possui um histórico de hospitalização em decorrência de um agravamento do quadro articular generalizado, derrame pleural e febre. O tratamento implementado incluiu as "gold drugs", Dpenicilamina e metotrexato durante admissão. Ao exame físico, foram observadas deformidades articulares compatíveis com a artrite reumatoide. A radiografia demonstrou erosões das articulações das mãos. Também foi identificada a presença de subluxação entre C1 e C2. O tratamento de escolha foi a metilprednisolona (Toussirot et al., 1995).

O segundo caso aborda um paciente de 77 anos com uma história de artrite reumatoide desde os 35 e que foi internado em decorrência de dor cervical. Ele também relata que sofre de dor em coluna de modo esporádico. Ao exame físico, exibe distorção das articulações da mão e presença de dor cervical importante. A radiografia revela uma subluxação entre $\mathrm{C} 1$ e $\mathrm{C} 2$ (Toussirot et al., 1995).

O terceiro caso é sobre uma paciente de 27 anos que sofre de artrite reumatoide desde os 19 e fazia uso do metotrexato. Ao exame físico, observa-se distorção de articulações periféricas (mãos, pulsos e pés). Em decorrência da queixa de dor lombar, foi realizado exame radiográfico que demonstrou sacroiliíte bilateral com erosão e esclerose (Toussirot et al., 1995).

Luthra, Ferguson e Conn (1976) relatam o caso de dois pacientes com uma apresentação típica dessa coexistência: ambos do sexo masculino que desenvolveram um quadro doloroso de caráter inflamatório em coluna vertebral e, após anos com o diagnóstico de espondilite anquilosante, iniciaram um quadro de dor e edema simétricos das articulações dos membros. O exame físico demonstrou a presença de nódulos em diversos tendões e sinovite ou espessamento sinovial das articulações acometidas. A radiografia das mãos exibiu sinais de erosão óssea, rarefação e redução dos espaços articulares. Já a radiografia de coluna demonstrou acometimento sacroilíaco e calcificações ligamentares em ambos os casos. Os medicamentos relatados foram prednisona e butazolidina no caso do primeiro paciente e aspirina, prednisona e ACTH no caso do segundo. Todos apresentaram falha em mostrar benefício (Luthra et al., 1976).

Tanto Rosenthal, Lidsky e Sharp (1968) quanto Huskisson e Hart (1970) descrevem o caso de dois pacientes do sexo masculino, com 73 e 80 anos de idade respectivamente, que seguem a ordem cronológica esperada para o desenvolvimento dessas doenças. Antes dos 30, cursaram com manifestações de espondilite anquilosante (um quadro de irite recorrente desde os 22 anos e um quadro de dor lombar aos 25 com presença de dor cervical e irite, respectivamente). Após um intervalo de tempo importante, manifestaram dor de caráter inflamatório em articulações dos membros (interfalangeanas proximais, joelhos, tornozelos, pulsos, ombros, pés e cotovelos) e presença de nódulos. Ao exame foi identificada limitação importante do movimento da coluna e deformidades nas articulações periféricas envolvidas. A radiografia exibiu obliteração das articulações sacroilíacas em ambos os casos e calcificação ligamentar (Rosenthal et al., 1970).

Mowat et al. (1976) descreve um total de 9 casos que apresentam essa coexistência, relatando o quadro clinico de seis homens e três mulheres. Seis apresentaram sintomas prévios de espondilite anquilosante (dor lombar e irite), e os outros três cursaram inicialmente com sintomas de poliartrite de articulações periféricas. Ao exame físico, todos apresentaram ou limitação ou abolição dos movimentos da coluna. $\mathrm{O}$ exame radiográfico demonstrou tanto alterações erosivas em articulações periféricas, principalmente nas mãos (com exceção de um dos casos em que o paciente apresentou apenas uma redução do 
espaço articular no exame de imagem das mãos) quanto anquilose sacroilíaca ou sacroiliíte (Mowat et al., 1976).

Tosum et al. (2005) descreveu a associação entre EA e SS em um mesmo paciente. O doente de 35 anos e do sexo masculino preenchia os critérios de New York modificados e, por esse motivo, o tratamento para EA foi instituído precocemente. Inicialmente, não havia nenhum sinal de uveíte no exame físico oftalmológico, sugerindo EA. A síndrome de Sjögren não foi considerada como diagnóstico diferencial no estágio inicial. No entanto, a persistência de xerostomia e xeroftalmia a despeito da retirada da amitriptilina sugeriu o diagnóstico secundário de SS. A presença de teste positivo de Schirmer, gamapatia monoclonal e anticorpos como o anti-SSA/Ro, anti-SSB/La, FAN e FR associados a achados específicos em uma biópsia de glândulas salivares confirmaram a síndrome de Sjögren.

Zhao et al. (2020) descreveu a coexistência de artrite reumatoide, espondilite anquilosante e síndrome de Sjögren em um mesmo paciente. O doente tinha 65 anos de idade e, desde os 30 anos, sentia fortes dores na região lombar, principalmente à noite, com rigidez articular matinal que durava mais de 1 hora. Por volta dos 42 anos de idade, ambas articulações do joelho e do tornozelo, as articulações interfalangeanas proximais e as metacarpais de ambas as mãos começaram a apresentar sinais de inflamação. Aos 45 anos de idade, começou a sofrer de intensa xerostomia a ponto de precisar da ingestão de água todas as vezes que ingeria algum tipo de alimento seco. Os dentes de sua arcada superior começaram a cair gradativamente com o passar dos anos. A xeroftalmia começou a ser frequente e o uso de colírios passou a ser constante. Ele consultou o departamento de reumatologia da equipe responsável em março de 2020 pela primeira vez. Os resultados laboratoriais mostraram interleucina-6 (IL-6) de $105 \mathrm{pg} / \mathrm{L}$ (faixa normal $<7 \mathrm{pg} / \mathrm{L}$ ), velocidade de hemossedimentação de $120 \mathrm{~mm} / \mathrm{h}$ (intervalo normal $<15 \mathrm{~mm} / \mathrm{h}$ ) e proteína $\mathrm{C}$ reativa de 77,63 mg/L (intervalo normal $<8 \mathrm{mg} / \mathrm{L}$ ). Os testes imunológicos mostraram anticorpo anti-CCP de 305,50 U/mL (intervalo normal $<17 \mathrm{U} / \mathrm{mL}$ ), FR $<$ 9,69 UI/mL (intervalo normal $<15,9$ UI/mL), FAN 1:1000, anticorpo anti-SSA/Ro (+), anticorpo anti-SSB/La (+), anticorpo anti-RO52 (+) e HLA-B27 (+). Radiografias simples de ambas as mãos mostraram dano ósseo moderado, diminuição do espaço articular e erosão óssea. A radiografia simples de tórax mostrou anquilose em alguns corpos vertebrais. A ressonância magnética da coluna lombar e articulações sacroilíacas mostrou múltiplas entesites de alguns corpos vertebrais e artrite sacroilíaca bilateral. A biópsia glandular labial mostrou infiltração linfocítica extensa. Finalmente, o paciente foi diagnosticado com EA e AR que coexistem com SS com base nos critérios de classificação da AR de acordo com ACR/EULAR 2010, nos critérios de classificação de New York de 1984 modificados para EA e na nova classificação padrão de 2016 para SS de acordo com ACR/EULAR 2010.

Goldstein e Steinfeld (1998) reportaram o caso de dois pacientes que preenchiam os critérios para o diagnóstico de SS e EA. Os fenótipos de histocompatibilidade de classe I e II foram surpreendentemente semelhantes em ambos pacientes e são a favor de uma associação casual.

O último caso analisado nesta revisão envolve um paciente de 69 anos que desenvolveu dor lombar aos 40, e aos 64 iniciou um quadro de envolvimento de articulações periféricas e aparecimento de nódulos (Wilkinson et al., 1958).

\section{Discussão}

Há poucos casos publicados na literatura acerca da associação entre artrite reumatoide, espondilite anquilosante e síndrome de Sjögren em um mesmo paciente. Nessas condições, as características clínicas, radiológicas e sorológicas de cada doença podem estar presentes de forma parcial ou completa.

A artrite reumatoide é uma doença inflamatória de etiologia multifatorial, que envolve tanto fatores genéticos, aos quais são atribuídos 50\% do risco (como a presença dos antígenos HLA-DR4 e HLA-DRB1), quanto gatilhos ambientais, sendo o tabagismo o principal deles. Cerca de 50-80\% dos pacientes possuem fator reumatoide positivo, anti-CCP positivo ou ambos. Os novos critérios diagnósticos levam em consideração o número e tamanho das articulações envolvidas, sorologia, presença de alterações em reagentes de fase aguda (PCR e VHS) e duração dos sintomas, além de não priorizar mais a 
presença de nódulos e erosões na radiografia, visto que são alterações que não são tão comuns em fases mais precoces da doença (Scott et al., 2010; Wasserman, 2011).

A manifestação clínica característica dessa doença é a presença de dor e rigidez em múltiplas articulações, com destaque para punhos, articulações interfalangeanas proximais e articulações metacarpofalangeanas (Wasserman, 2011). De fato, os pacientes apresentados nos relatos demonstraram essas características de envolvimento. Contudo, as articulações dos pés também foram acometidas em uma quantidade importante de casos, e envolvimento de articulações maiores dos membros como ombros, cotovelos, joelhos e tornozelos também foram relatadas, porém, em menor quantidade de casos.

A espondilite anquilosante é uma doença inflamatória crônica que acomete principalmente o sexo masculino. Normalmente se apresenta entre os 30 e 50 anos de idade, mas pode aparecer em idade mais precoce. Os paradigmas dessa doença são dor de caráter inflamatório e rigidez na região do dorso. Contudo, o paciente também pode cursar com outros sintomas como envolvimento de articulações periféricas (joelhos, mãos e pés), entesite (principalmente na região do calcâneo), manifestações extra-articulares como uveíte anterior e irite, e sintomas constitucionais como a fadiga (Golder et al., 2013; Bond, 2013). De fato, apenas 6 pacientes cursaram com ausência de dor de caráter inflamatório na região do dorso. Cerca de 25-40\% dos pacientes cursam com uveíte anterior, podendo essa e a irite serem as primeiras manifestações da doença no indivíduo (BOND, 2013). É o que ocorre em um dos pacientes de Mowat et al. (1976) e no paciente descrito por Rosenthal, Lidsky e Sharp (1968), que, apesar de não manifestarem os sintomas mais típicos, desenvolveram um quadro de irite.

$\mathrm{O}$ envolvimento de articulações periféricas pode gerar confusão diagnóstica e mimetizar um quadro de artrite reumatoide. Contudo, é necessário se atentar para as diferenças que podem ser observadas: geralmente o acometimento periférico da espondilite é assimétrico, desenvolve-se nos membros inferiores e envolve uma quantidade menor de articulações (o paciente desenvolve uma oligoartrite, ou seja, < ou $=4$ articulações acometidas) (Golder et al., 2013).

Existem poucos relatos sobre a coexistência de AR com EA. O HLA-B27 contribui para a EA, enquanto o HLA-DR4 está associado à AR. Nenhuma correlação foi encontrada entre HLA-B27 e AR. Uma pesquisa de Toussirot e Acquaviva (1995) mostrou que 6,6\% dos pacientes com AR podem ter HLA-B27 positivo. A presença de HLA-B27 em pacientes com AR não aumenta a incidência de entesite ou inflamação da articulação sacroilíaca. Da mesma forma, um FR positivo em um paciente com EA não aumenta o risco de erosão articular periférica. A grande maioria dos pacientes com AR coexistindo com espondiloartropatias (EpA) (incluindo EA) foram considerados FR e anti-CCP positivos. Pacientes positivos para EA costumam coexistir com artrite periférica. $\mathrm{O}$ acometimento é principalmente assimétrico, geralmente envolvendo uma única grande articulação, e a erosão óssea raramente é encontrada. Na AR, o envolvimento esquelético axial raramente é observado, exceto na coluna cervical. No entanto, o estudo de Can G. et al. (2013) sugere alta frequência de características de EpA, como dor lombar inflamatória (16,8\%), sacroilíite $(2,4 \%)$ e entesite $(41,9 \%)$ em pacientes com AR. O paciente do estudo de Zhao et al. (2020) apresentou HLA e anti-CCP positivos e FR negativo. Ele primeiro mostrou sintomas típicos de espondiloartropatia (dor lombar inflamatória) e, em seguida, gradualmente mostrou artrite reumatoide típica, edema e dor nas pequenas articulações simétricas. Isso pode estar relacionado às diferentes idades de prevalência de EA e AR.

Clayman e Reinertsen (1978) não encontraram na literatura outro caso que correspondesse a associação entre artrite reumatoide, espondilite anquilosante e síndrome de Sjögren. Porem, 5 relatos sobre 14 pacientes portadores de uma associação entre artrite reumatoide e espondilite anquilosante foram encontrados por eles.

Os dados epidemiológicos sugerem que o perfil de paciente que apresenta essa ocorrência simultânea das duas doenças é de um indivíduo do sexo masculino, que desenvolve espondilite anquilosante em uma idade mais precoce e, somente anos depois, abre um quadro de artrite reumatoide (Clayman et al., 1978). A maioria dos casos apresentados corroborou com esse dado. Contudo, a paciente do sexo feminino de Barczyńska et al. (2015), de Varga et al. (2009), bem como os 3 pacientes relatados por Toussirot e Acquaviva (1995) (uma mulher e dois homens), e 3 dos 9 pacientes de Mowat et al. (1976), 
apresentaram sintomas de artrite reumatoide precedendo a descoberta ou início dos sintomas da espondiloartropatia. É importante ter em mente, contudo, que dos 3 pacientes de Toussirot e Acquaviva (1995), apenas um cursou com dor em coluna de caráter inflamatório. Logo, é possível que a espondilite anquilosante tenha aparecido em uma idade mais precoce e se manifestado de forma oligossintomática ou assintomática.

Segundo Mowat et al. (1976), em apenas 1 dos casos pode-se afirmar que a artrite reumatoide precedeu de fato o desenvolvimento da espondiloartropatia. Nos outros 2, não foi possível determinar a data de início da espondilite anquilosante em decorrência da ausência de sintomas.

Clayman e Reinertsen (1978), Guo et al. (2011) e Baksay et al. (2011) discutem a incongruência entre a prevalência de casos esperados da associação entre artrite reumatoide e espondilite anquilosante e a escassez de casos relatados na literatura. Algumas das possíveis explicações sugeridas para esse achado foram o fato de formas moderadas dessas doenças dificultarem o diagnóstico de ambas em um mesmo paciente, a interferência do sexo do portador, observação e exame clínico insuficientes, o abandono da investigação clínica após a descoberta de uma das doenças e a supressão de uma das doenças em decorrência do inicio do tratamento imunossupressor para a outra.

Guo et al. (2011), Baksay et al. (2011) e Varga et al. (2009) apresentam pacientes que manifestaram como possível gatilho de uma das doenças a gravidez. No caso da primeira, sintomas de artrite reumatoide se apresentaram após a gravidez, o que pode ser o fator que levou a ocorrência simultânea dessas duas doenças. De fato, um estudo do tipo caso-controle realizado na Suécia mostrou que a gravidez pode estar associada a um risco aumentado de desenvolvimento de artrite reumatoide negativa para anti-CCP nas mulheres em idade reprodutiva (Orellana et al., 2014). Outro estudo que corrobora com esse achado sugere que existe um risco aumentado de desenvolver a doença nos primeiros 3 meses após o parto e essa tendência persiste até nove meses após o evento (Littlejohn, 2020). Contudo, alguns estudos entram em discordância ao demonstrar que existe um risco reduzido de desenvolver artrite reumatoide em pacientes que já passaram pela gravidez em algum momento da vida, quando comparadas com mulheres nulíparas (Hazes et al., 1990). No caso de Baksay et al. (2011) e Varga et al. (2009), algum tempo após o parto, a paciente cursou com dor e rigidez da coluna vertebral, que, mais tarde, resultou no diagnóstico de espondilite anquilosante.

Cerca de 90-95\% dos pacientes portadores da doença possuem o HLA-B27 positivo (Barczyńska et al., 2015). Esse dado está de acordo com os achados desse artigo, visto que a maior parte dos relatos aborda indivíduos com positividade para esse antígeno. Contudo, 2 dos 3 pacientes de Toussirot e Acquaviva (1995) exibem HLA-B27 negativo. Esse achado incomum levanta uma possibilidade citada pelo próprio artigo de que o acometimento da coluna vertebral seja na verdade em decorrência da própria artrite reumatoide. Apesar de incomum, segundo alguns autores, esses pacientes podem manifestar um processo inflamatório da articulação sacroilíaca, apesar da anquilose não ser esperada (Martel et al., 1961). O mais esperado, no caso de um acometimento da coluna por AR, é o envolvimento da região cervical (Martel et al., 1961). Dois dos três pacientes desse relato (justamente os que apresentam HLA-B27 negativo) apresentaram subluxação atlantoaxial, o que fortalece essa suposição. Contudo, ambos também apresentam anquilose sacroilíaca.

No que diz respeito ao fator reumatoide, a maior parte dos pacientes com artrite reumatoide apresentam positividade para esse marcador. Apesar de sensível, ele não apresenta boa especificidade, diferente do anti-CCP, que é considerado o mais específico, mas nem sempre está presente (Barczyńska et al., 2015). De fato, apenas dois pacientes dessa revisão apresentaram resultado negativo para o fator reumatoide. Na grande maioria dos relatos, contudo, o resultado do anti-CCP ou não foi relatado ou nem sequer testado.

As principais alterações radiográficas encontradas na artrite reumatoide incluem rarefação óssea, erosões marginais, redução do espaço articular, deformidades, subluxações e anquilose; achados esses observados em diversos casos da presente revisão. É importante ter em mente que a radiografia identifica consequências mais tardias desse processo inflamatório, e 
outros métodos de imagem, como a ressonância magnética, são capazes de identificar sinais mais precoces como sinovite e edema ósseo (Cerri, 2017).

A radiografia apresenta as consequências do processo inflamatório na coluna e articulações sacroilíacas. Logo, o aparecimento de alterações nesse exame de imagem costuma ser tardio. Ainda assim, alterações na radiografia são usadas como critério para o diagnóstico da espondilite anquilosante. É necessária a existência de, no mínimo, alterações bilaterais de grau 2 ou alterações de grau 3 ou 4. No grau 2, o paciente apresenta áreas pequenas de erosão e esclerose, mas o espaço articular sacroilíaco está preservado. O grau 3 se caracteriza por redução do espaço ou fusão parcial dessa articulação e o grau 4 representa a fusão completa, apresentação observada em muitos dos casos descritos. Na coluna, as alterações variam desde o aparecimento do sinal de Romanus ou do ângulo brilhante (alteração precoce na qual se observam irregularidades e erosões das bordas vertebrais) até a "coluna em bambu", que representa a anquilose dos corpos vertebrais. Outro achado que foi retratado em alguns dos relatos dessa revisão consiste na presença de calcificação do ligamento espinhal (Golder et al., 2013; Bond, 2013; Cerri, 2017).

A incidência de coexistência entre SSi e EA é muito baixa. No entanto, na pesquisa de Kobak (2006), uma alta prevalência de SS em pacientes com EA (10\%) foi observada e, paralelamente, a SSi foi muito mais comum em mulheres com EpA em alguns estudos. Esses pacientes têm alguns pontos comuns, como idade avançada, sexo feminino, alta frequência de FAN positivo a presença de SSi associada. Embora os pacientes com EpA e SSi não tenham formas mais graves de EpA, eles parecem menos responsivos aos medicamentos de segunda linha e/ou aos anti-inflamatórios não esteroidais.

As espondilartropatias e as doenças do tecido conjuntivo (DTC) são entidades clinicamente distintas que, à primeira vista, parecem ter pouco em comum. No entanto, uma ligação entre EpA e DTC foi recentemente sugerida por um estudo no qual uma prevalência mais alta de Síndrome de Sjögren e sintomas associados foi relatada em pacientes com espondilite anquilosante e EpA indiferenciada. Outra ligação entre EpA e DTC é um possível efeito colateral de um DMARD amplamente usado para tratar EpA: sulfassalazina (SAS). Foi relatado que SAS induzia anticorpos antinucleares (ANA) e síndromes semelhantes ao lúpus eritematoso sistêmico (LES), como o lúpus induzido por drogas. O relato de Brandt et al. (2002) descreve um paciente do sexo masculino, branco, de 54 anos, HLA B27-positivo com EA e alguns sindesmófitos que, após 15 anos de doença, desenvolveu SS com envolvimento de glândulas salivares, síndrome de Raynaud e anticorpos anti-SSA/Ro. Então, 20 anos após o início da EA, ele ficou gravemente doente, evoluindo com miosite e miocardite graves, juntamente com sinais de artrite e títulos de autoanticorpos altamente elevados reconhecendo U1RNP; sua condição foi interpretada como doença mista do tecido conjuntivo (DMTC). O paciente havia sido tratado apenas com SAS e azatioprina (AZA) várias vezes durante os últimos anos, pois não tolerava outros DMARDs. Uma combinação de ambas as drogas foi prescrita 3 semanas antes de um surto grave por causa da alta atividade da doença associada a uma artrite periférica dolorosa das articulações metacarpofalangeanas e interfalangeanas proximais que, no entanto, não mostraram erosões radiográficas. Foi descrito, portanto, o raro desenvolvimento de DMTC em um paciente com EA e relatado, pela primeira vez, o aparecimento de DMTC potencialmente desencadeada por sulfassalazina.

\section{Conclusão}

A prevalência da coexistência de artrite reumatoide, espondilite anquilosante e síndrome de Sjögren em um mesmo paciente é rara de acordo com o perfil avaliado e a metodologia aplicada. A totalidade dos casos foi publicada como ocorrência raríssima em periódicos. Os dois principais estudos publicados na literatura referentes à associação das três doenças indicam que ela acomete preferencialmente homens a mulheres, com início naqueles com faixa etária entre 25 e 35 anos. Os estudos sobre a associação em crianças e adolescentes são escassos e, quando presentes, pouco conclusivos. Do ponto de vista sorológico, ambos estudos demonstraram a presença de fator reumatoide positivo e HLA-B27 positivo. Um dos estudos 
mostrou ainda a presença de anticorpo anti-SSA/Ro positivo, anti-SSB/La positivo, fator antinuclear positivo, anticorpo antiCCP positivo e anticorpo anti-RO52 positivo. A análise radiográfica dos estudos demonstrou em comum a presença de osteoporose, diminuição do espaço articular e erosão óssea especialmente nas articulações metacarpofalangeanas. Os pacientes possuíam em comum a presença de dor lombar precoce - relatada antes dos 30 anos de idade - especialmente noturna, com rigidez articular matinal com duração superior a uma hora.

Tendo em vista a raridade dessa associação e a escassez de dados clínicos, um diagnóstico claro é crucial para a decisão do plano terapêutico, uma vez que as estratégias de tratamento das três doenças são distintas e individualizadas.

Uma sugestão para futuros trabalhos envolve o estudo das manifestações clínicas e, sobretudo, dos aspectos sorológicos associado ao perfil genético de pacientes portadores de outras associações triplas ou associações duplas pouco usuais, como a presença concomitante de artrite reumatoide e síndrome de Sjögren.

\section{Agradecimentos}

Os autores agradecem profundamente aos revisores anônimos por seus enriquecedores comentários, que ajudaram a melhorar a apresentação e a qualidade deste artigo científico.

\section{Referências}

Alani, H.; Henty, J.R.; Thompson, N.L.; Jury, E.; Ciurtin, C. (2018). Systematic review and meta-analysis of the epidemiology of polyautoimmunity in Sjogren's syndrome (secondary Sjogren's syndrome) focusing on autoimmune rheumatic diseases. Scandinavian Journal of Rheumatology, v. 47, n. 2, p. 141154, 4 mar. 2018.

Aletaha, D. et al. (2010). Rheumatoid arthritis classification criteria: an American College of Rheumatology/European League Against Rheumatism collaborative initiative. Arthritis and Rheumatism, v. 62, n. 9, p. 2569-2581, 2010.

Azevedo, V. F.; Buiar, P. G. (2012). Concomitância de artrite reumatoide e espondilite anquilosante em um único paciente: importância dos novos critérios de classificação. Revista Brasileira de Reumatologia, [S. l.], p. 111-119, 26 nov. 2012.

Baksay, B. et al. (2011). Coexistence of ankylosing spondylitis and rheumatoid arthritis in a female patient. Clinical Rheumatology, v. 30, n. 8, p. 1119-1122. Barczyńska, T. A. et al. (2015). Coexistence of rheumatoid arthritis and ankylosing spondylitis. Reumatologia, v. 53, n. 5, p. 279-285.

Bond, D. Ankylosing spondylitis: diagnosis and management. (2013). Nursing standard (Royal College of Nursing (Great Britain): 1987 ), v. 28, n. 16-18.

Brandt, J. et al. (2002). Co-occurrence of spondyloarthropathy and connective tissue disease: development of Sjögren's syndrome and mixed connective tissue disease (MCTD) in a patient with ankylosing spondylitis. Clinical and experimental rheumatology, Italy, https://pubmed.ncbi.nlm.nih.gov/11892716/

Brasil. Ministério da Saúde. Secretaria de Atenção à Saúde. (2015). Portaria nº 996, de 30 de setembro de 2015. Aprova o Protocolo Clínico e Diretrizes Terapêuticas da Artrite Reumatoide. Diário Oficial da União, Brasília (DF), $1^{\circ}$ de outubro de 2015, Seção 1, p. 99.

Can, G.; Solmaz, D.; Binicier, O.; Akar, S.; Birlik, M.; Soysal, O.; Akkoc, N.; Manisali, M.; Onen, F. (2013). High frequency of inflammatory back pain and other features of spondyloarthritis in patients with rheumatoid arthritis. Rheumatology International, 33:1289-1293. https://doi.org/ 10.1007/s00296-0122553-7

Carvalho, M.P. (2011). Periódico do Serviço de Reumatologia da Faculdade de Medicina da Universidade Federal de Minas Gerais. 21 de maio de 2011. Cerri, G.G. (2017). Tratado de radiologia. 1.Ed. Barueri: Manole.

Chiarello, B.; Driusso, P.; Radl, A. (2015). Fisioterapia Reumatológica. Barueri, SP: Manole.

Clayman, M. D.; Reinertsen, J. L. (1978). Ankylosing Spondylitis with Subsequent Development of Rheumatoid Arthritis, Sjögren'S Syndrome, and Rheumatoid Vasculitis. Arthritis \& Rheumatism, v. 21, n. 3, p. 383-389.

Cruz Filho, A. (2013). Espondilite Anquilosante. Clínica Reumatológica. Rio de Janeiro: Guanabara Koogan.

Daniels, T.E.; Whitcher, J.P. (1994). Association of patterns of labial salivary gland inflammation with keratoconjunctivitis sicca. Analysis of 618 patients with suspected Sjogren's syndrome. Arthritis Rheum. 37(6):869-77.

De Carvalho, A.; Graudal, H. (1980). Sacroiliac joint involvement in classical or definite rheumatoid arthritis. Acta Radiologica, v. 21 , n. 3, p. $417-423$.

Drumond, S.N.; Pinto, S.M. (2001). Artroplastia total do quadril em Espondilite Anquilosante. Revista Brasileira de Reumatologia, vol. XI, - ${ }^{\circ}$ 3, junho/2001.

Estrela, C. (2018). Metodologia Científica: Ciência, Ensino, Pesquisa. Editora Artes Médicas.

Felberg, S.; Dantas, P. E. C. (2006). Diagnóstico e tratamento da síndrome de Sjögren. Arquivos Brasileiros de Oftalmologia, v. 69, n. 6, p. 959-963. 
Fraenkel, L. et al. (2021). American College of Rheumatology Guideline for the Treatment of Rheumatoid Arthritis. Arthritis Care and Research, v. 73, n. 7, p. 924-939.

Furst, D. E. (2014). Glucocorticoid withdrawal [Internet]. Waltham (MA): UpToDate Inc.. http://www.uptodate.com/contents/glucocorticoid-withdrawal.

Gabriel, M.S.; Petit, J.D.; Carril, M.L.S. (2011). Fisioterapia em Traumatologia, Ortopedia e Reumatologia. Rio de Janeiro: Ed. Revinter.

Golder, V.; Schachna, L. (2013). Ankylosing spondylitis: An update. Australian Family Physician, v. 42, n. 11, p. 780-784.

Guo, Y. Y. et al. (2011). Coexisting ankylosing spondylitis and rheumatoid arthritis: A case report with literature review. Chinese Medical Journal, v. 124, n 20, p. 3430-3432.

Harrold, L. R. et al. (2020). Prevalence of Sjögren's syndrome associated with rheumatoid arthritis in the USA: an observational study from the Corrona registry. Clinical Rheumatology, v. 39, n. 6, p. 1899, 1 jun. 2020.

Hazes, J. M. W. et al. (1990). Pregnancy and the risk of developing rheumatoid arthritis. Arthritis \& Rheumatism, v. 33, n. 12, p. $1770-1775$.

Houli, Jacques; Klein, Boris; Morais de Sá, C.A. (2012). Espondilite Anquilosante - revisão de 53 pacientes em duas épocas diferentes. Revista Brasileira de Reumatologia, vol. XX - $\mathrm{n}^{\circ} .2$.

Huskisson, E. C.; Hart, F. D. (1970). Ankylosing Spondylitis and Rheumatoid Arthritis. Journal of the Royal Society of Medicine, v. 63, n. 6, p. 620.

Kasper, D.L. et al. (2020).Harrison Medicina Interna, v.2.20a . Edição. Rio de Janeiro: McGrawHill.

Klarenbeek, N. B. (2010). Recent advances in the management of rheumatoid arthritis [Internet]. British Medical Journal, London, v. 341 , c 6942 http://dx.doi.org/10.1136/bmj.c6942.

Kobak, S. (2006). Sjögren's syndrome in patients with ankylosing spondylitis. Clin Rheumatol, [S. l.], p. 34-37.

Laurindo, I.M.M. et. al. (2007). Artrite Reumatoide: Diagnóstico e Tratamento. Revista Brasileira de Reumatologia, vol. 44 - nº 6, p. 435-442.

Lawall, M. D. A. et al. (2006). Síndrome de Sjögren: relato de caso clínico. Revista da Faculdade de Odontologia - UPF, v. 11, n. 2, p. 77-80.

Lindes, S.M.; Valkengurg, H.A.; De Jongh, B.M. (1984). The risk of developing ankylosing spondylitis in HLA-B27 positive individuals. A comparison of relatives of spondylitis patients with the general population. ArthritisRheum; 27:241-9.

Littlejohn, E. A. (2020). Pregnancy and rheumatoidarthritis. Best Practice and Research: Clinical Obstetrics and Gynaecology, v. 64, p. 52-58.

Luthra, H. S.; Ferguson, R. H.; Conn, D. L. (1976). Coexistence of ankylosing spondylitis and rheumatoid arthritis. Arthritis \& Rheumatism, v. 19, n. 1, p. $111-114$.

Ma, G.; Steinfeld, S. (1988). Ankylosing spondylitis with primary Sjögren's syndrome: the first two case-reports. Revuedurhumatisme (English ed.), France. <https://pubmed.ncbi.nlm.nih.gov/9670336/>

Major P.; Resnick, D.; Dalinka, M.; Kline, P. (1980). Coexisting rheumatoid arthritis and ankylosing spondylitis. AJR Am J Roentgenol; 134(5):1076-9.

Martel, W.; Duff, I. F. (1961). Pelvo-spondylitis in rheumatoidarthritis. Radiology, v. 77, p. 744-756.

Mendes, W.; Menezes, A.; Sobral, S. (2005). Reabilitação na Espondilite Anquilosante. Revista Brasileira de Reumatologia, vol. XV - nº 3.

Meirelles, E.S. (2015). Espondilite Anquilosante e Exercícios. Doença e Prevenção. Rio de Janeiro: Guanabara Koogan.

Moreira, C.; Carvalho, M.A. (2001). Reumatologia - diagnóstico e tratamento. Rio de Janeiro: $2^{\mathrm{a}}$ edição, Medsi.

Moreira, C.; Carvalho, M.A. (2006). Noções práticas de Reumatologia. Vol. II. Belo Horizonte: Health.

Mota, L. M. H. D. et al. (2018) recommendations of the Brazilian Society of Rheumatology for the pharmacological treatment of rheumatoid arthritis. Advances in rheumatology (London, England), v. 58, n. 1.

Mowat, A. G. et al. (1976). Rheumatoid arthritis and ankylosing spondylitis occurring together. British Medical Journal, v. 1, n. 6013, p. 804-807.

Orellana, C. et al. (2014). Parity and the risk of developing rheumatoid arthritis: Results from the Swedish Epidemiological Investigation of Rheumatoid Arthritis study. Annals of the Rheumatic Diseases, v. 73, n. 4, p. 752-755.

Pereira, I. A. et al. (2009). Recomendações nacionais baseadas em evidências científicas e opiniões dos especialistas sobre o uso do metotrexato nas doenças reumáticas, especialmente na artrite reumatoide: resultados da iniciativa 3E do Brasil. Revista Brasileira de Reumatologia, São Paulo, v. 49, n. 4, p. 346-361. Disponível em: http://dx.doi.org/10.1590/S0482-50042009000400003.

Rezende, M.C. (2016). Sociedade Brasileira de Reumatologia - Espondilite Anquilosante baseado no texto “Arthritis Foundation”.

Rojas-Villarrag A, A. et al. (2012). Introducing polyautoimmunity: secondary autoimmune diseases no longer exist. Autoimmune diseases, v. 2012 , n. 1.

Rosenthal, S. H.; Lidsky, M. D.; Sharp, J. T. (2006). Arthritis with Nodules Following Ankylosing Spondylitis. JAMA: The Journal of the American Medical Association, v. 206, n. 13, p. 2893-2894.

Scola, Rosana Herminia; Lin, Katia; Iwamoto, Fabio Massaiti; Arruda, Walter Oleschko; Werneck, Lineu Cesar. (2001). Ankylosing Spondylitis and Central Core Disease: a Case Report. 
Scott, D. L.; Wolfe, F.; Huizinga, T. W. J. (2010). Rheumatoid arthritis. The Lancet. Anais. Elsevier B.V.

Shafia S.; Sofi F.A.; Dilafroze, R. R.; Javeed S.; Shah Z.A. (2016). The association between TNF $\alpha$ gene polymorphisms and susceptibility to rheumatoid arthritis in an ethnic Kashmiri population: relationship with disease activity and severity markers. International Journal of Rheumatic Diseases, 2016 Apr;19(4):362-9. doi: 10.1111/1756-185X.12270. Epub 2013 Dec 30. PMID: 24382334.

Shiboski, C. H. et al. (2016). American College of Rheumatology/European League Against Rheumatism Classification Criteria for Primary Sjögren's Syndrome: A Consensus and Data-Driven Methodology Involving Three International Patient Cohorts. Arthritis \& rheumatology (Hoboken, N.J.), v. 69, n. 1, p. $35-45$.

Spoorenberg, A.; Van Der Heijde, D.; De Klerk, E.; Dougados, M. (1999). Relative value of erythrocyte sedimentation rate and C-reactive protein in assessment of disease activity in ankylosing spondylitis. Jornal of Rheumatology; 26(4):980-4.

Tosun, M. et al. (2005). Coexisting ankylosing spondylitis and Sjogren's syndrome: a case report. Rheumatology International Germany. $<$ https://pubmed.ncbi.nlm.nih.gov/15761725/>

Toussirot, E.; Acquaviva, P. C. (1995). Coexisting rheumatoid arthritis and ankylosing spondylitis discussion of 3 cases with review of the literature. Clinical Rheumatology, v. 14, n. 5, p. 554-560.

Universidade Federal de Alfenas. (2006). Manual de Normalização para Elaboração de Trabalhos Acadêmicos, Dissertações e Teses da Unifal-MG. Alfenas. Valim, V. et al. (2015). Recomendações para o tratamento da síndrome de Sjögren. Revista Brasileira de Reumatologia, v. 55, n. 5, p. $446-457$.

Van Der Linden, S. et al. (1984). The risk of developing ankylosing spondylitis in HLA-B27 positive individuals. A comparison of relatives of spondylitis patients with the general population. Arthritis and Rheumatism, v. 27, n. 3, p. 241-249, 1984.

Van Der Linden, S.; Valkenburg, H.A.; Cats, A. (1984). Evaluation of diagnostic criteria for ankylosing spondylitis. Arthritis and Rheumatism, 1984; 27:3618.

Van Der Heijde, D. et al. (2017). 2016 update of the ASAS-EULAR management recommendations for axial spondyloarthritis. Annals of the rheumatic diseases, v. 76, n. 6, p. 978-991, 1 jun. 2017.

Varga, E. et al. (2009). Egy betegség két arca: szeronegatív rheumatoid arthritist követoen kialakuló spondylarthritis ankylopoetica: Esetbemutatás a 20 éves reumatológiai osztály anyagából. Orvosi Hetilap, v. 150, n. 43, p. 2000-2003.

Vitali, C. et al. (2002). Classification criteria for Sjögren's syndrome: a revised version of the European criteria proposed by the American-European Consensus Group. Annals of the rheumatic diseases, v. 61, n. 6, p. 554-558, 2002.

Ward, M. M. et al. (2019). Update of the American College of Rheumatology/Spondylitis Association of America/Spondyloarthritis Research and Treatment Network Recommendations for the Treatment of Ankylosing Spondylitis and Nonradiographic Axial Spondyloarthritis. Arthritis \& rheumatology (Hoboken, N.J.), v. 71, n. 10, p. 1599-1613.

Wasserman, A. M. (2011). Diagnosis and management of rheumatoid arthritis. American Family Physician, v. 84, n. 11, p. 1245-1252.

Wilkinson, M.; Bywaters, E. G. (2008). Clinical features and course of ankylosing spondylitis; as seen in a follow-up of 222 hospital referred cases. Annals of the rheumatic diseases, v. 17, n. 2, p. 209-228.

Zhao, G. W. et al. (2020). Ankylosing spondylitis coexists with rheumatoid arthritis and Sjögren's syndrome: a case report with literature review. Clinical. Rheumatology, v. 40, n. 5, p. 2083-2086, 1 maio 2021. 